\title{
De la littératie aux littératies : conceptions et frontières
}

Jean-Louis Chiss

\section{(2) OpenEdition}

1 Journals

\section{Édition électronique}

URL : http://journals.openedition.org/rdlc/3943

DOI : $10.4000 /$ rdlc.3943

ISSN : 1958-5772

Éditeur

ACEDLE

\section{Référence électronique}

Jean-Louis Chiss, «De la littératie aux littératies :

conceptions et frontières », Recherches en didactique des langues et des cultures [En ligne], 9-2 | 2012 mis en ligne le 10 septembre 2018, consulté le 21 décembre 2020. URL : http:// journals.openedition.org/rdlc/3943; DOI : https://doi.org/10.4000/rdlc.3943

Ce document a été généré automatiquement le 21 décembre 2020.

\section{c) (i) $९$}

Recherches en didactique des langues et des cultures is licensed under a Creative Commons AttributionNonCommercial-NoDerivatives 4.0 International License 


\title{
De la littératie aux littératies : conceptions et frontières
}

\author{
Jean-Louis Chiss
}

1 On retrouvera, dans cette brève intervention, les quelques directions de réflexion que j'ai soumises en conclusion de cette journée d'études NeQ sur «Les littératies $»^{1}$. On ne peut qu'être frappé à l'écoute des communications dont certaines inspirées par le courant des «New Literacy Studies» (voir Langage \& société $n^{\circ} 133,2010$ ) par l'extension d'un domaine que les problématiques initiatiques de Jack Goody et David Olson avaient semblé circonscrire. L'abondance terminologique actuelle, dans un champ de recherches de plus en plus proliférant, donne une impression d'éclatement ou de dilution comme si toutes les pratiques culturelles et sociales relevaient peu prou de la «littératie »: le son, l'image, le corps dans le déploiement de la multimodalité (« littératies multimodales »), le digital et la «littératie numérique», tout le domaine de la communication, et les activités artistiques (le hip hop et le rap). Dans cette liste ouverte figurent les « littératies locales » spécifiées en fonction des ancrages sociaux : « littératie académique », « littératie du lieu de travail » et "littératie de mobilité » pour travailler les identités liées à la migration avec le rôle des " médiateurs de littératie "; à quoi s'ajoutent les plurilittératies scolaires et multimodales pour la reconnaissance de modes d'expression alternatifs en résonance avec les «pédagogies critiques » et tous les courants contestataires des inégalités et de l'échec des systèmes éducatifs. C'est aussi dire le poids dans ces orientations de l'idéologisation de la notion princeps de « literacy ». Nous y reviendrons.

2 Il ne s'agit pas de contester la pluralisation des « littératies » au profit d'un concept autosuffisant qui serait indifférent aux variations et aux contextualisations. Scribner et Cole (voir le $\mathrm{n}^{\circ}$ de Langage \& société), et Goody discutant leurs thèses, mettent en évidence la pluralité des formes sociales d'usage de l'écrit dans une communauté donnée, ce qu'il ne me gêne pas d'appeler les "cultures de l'écrit", et il est parfaitement nécessaire d'examiner les modes d'intervention de l'écrit dans les domaines de la vie sociale (famille, école, travail), donc de repérer les fonctions que remplit l'écrit dans les sociétés plus ou moins littératiées. Il est tout aussi légitime, et au fond prescrit par le concept lui-même, de mesurer l'influence de la littératie, tant «traditionnelle » que «numérique », sur les 
processus de pensée et l'apprentissage, donc de clairement argumenter sur la relation entre scolarisation et littératie, de montrer les bénéfices de cette problématique pour la didactique et spécifiquement pour l'enseignement des langues. Dans le contexte français, cette livraison de $\mathrm{NeQ}$, venant après des numéros de revues de didactique du français comme Pratiques ou Le français aujourd'hui (voir la bibliographie), atteste de possibilités heuristiques, déjà précédemment débattues (Chiss, 2012).

Mais force est de constater que les modalités d'extension du champ propre à la littératie ne sont pas toutes de même nature. Outrepassant largement le domaine de l'écrit, depuis l'acculturation jusqu'aux activités lettrées, les recherches proposées dans l'aire angloaméricaine, s'inscrivent dans une sociologie des pratiques culturelles qu'ont illustrée, chacun à leur manière dans le contexte francophone, des auteurs comme Pierre Bourdieu ou Bernard Lahire. On pourrait même affirmer que certains de ces travaux relèvent d'une sémiologie générale, telle qu'elle peut être induite de l'orientation d'un Greimas s'acheminant vers une théorie d'ensemble, à rebours du « point de vue sémiologique » de Saussure (voir Chiss et Puech, 1999, deuxième partie, chapitre 2). Si la question des limites disciplinaires, des frontières et des constructions de l'objet de connaissance se pose toujours, ce n'est pas dans les mêmes termes: alors même que pour traiter du " continent écriture ", Roy Harris proposait aussi une « sémiologie " (voir Chiss et Puech, op. cit, troisième partie, chapitre 2), la relativisation de la place de l'écrit, des processus de lecture-écriture, au sein des recherches des New Literacy Studies déplace finalement plus qu'elle n'enrichit la notion de littératie(s). En fait d'extension, ce que Goody a d'abord apporté et qui m'a semblé déterminant, en particulier pour les didactiques, c'est le passage de la textualité à la scripturalité d'une part et, d'autre part, l'inscription de la littératie dans les cultures linguistiques et éducatives. On pouvait être fondé par exemple à parler d'une « littératie à la française » qui ne saurait ignorer la dimension historique des conceptualités, représentations et pratiques. La pluralisation des « littératies » trouve à se justifier tout en conservant son objet d'investigation. Si d'aucuns, en France, reprochaient déjà à la littératie son caractère trop général, que dire alors désormais ?

Mais c'est qu'il y a sans doute "généralité " et "généralité ». En introduisant les questions du «local» et du "vernaculaire» dans une conceptualité jugée épistémologiquement neutre dans le meilleur des cas et souvent limitée à une dimension cognitive peu soucieuse de la réalité des pratiques sociales dans leur différentialisme inégalitaire, les critiques de Goody (par exemple Brian Street et ses épigones) ont souhaité mettre un terme à une prétendue survalorisation de l'écrit susceptible d'occulter ou de marginaliser les cultures des classes populaires, des immigrés et des groupes minoritaires. On peut d'autant moins refuser l'idée que la possession de la lectureécriture comme " technologie de l'intellect » induise une relation de pouvoir au sein des sociétés qu'elle fait partie intégrante de la fabrique de la littératie. Mais il y a lieu de s'interroger sur une pensée dualiste qui fait des « littératies locales » des lieux de contrepouvoir. En traduisant le titre du livre de Richard Hoggart (1957) The Uses of Literacy par La culture du pauvre (1970), la sociologie bourdieusienne avait déjà fait œuvre politique...

$\mathrm{Du}$ « grand partage » entre sociétés dominées par l'oralité et sociétés littératiées maintes fois revisité par Goody jusqu'à son dernier ouvrage (2010), peu suspect de complaisance à l'égard de l'occidentalocentrisme, le trajet de l'ethnologue et sa problématique de la « literacy » ont plus déconcerté les milieux lettrés qu'ils ne les ont confortés. Ceci est particulièrement vrai en France où la réception de l'œuvre s'est opérée loin des préoccupations de la culture littéraire et classiquement humaniste dans un contexte 
d'interrogations sur les formes et espaces des illettrismes (de l'école au monde du travail), sur l'immigration et la diversité culturelle des littératies, d'intérêt pour les «écritures urbaines » et les écrits sociaux, de travail sur l'échec scolaire en langue maternelle, la «maitrise de la langue », l'apprentissage de la lecture, l'organisation scripturale des disciplines scolaires. C'est, en tout cas, ainsi que la littératie m'a interpellé comme linguiste et didacticien des langues.

\section{BIBLIOGRAPHIE}

Chiss, J.-L (2012). L'écrit, la lecture et l'écriture : théories et didactiques, Paris : L'Harmattan.

Chiss, J.L. et Puech, C. (1999). Le langage et ses disciplines, Paris, Bruxelles : Éditions Duculot.

Goody, J. (2010). Le Vol de l'histoire. Comment l'Europe a imposé le récit de son passé au reste du monde, Paris : Gallimard [trad. fr. de The Theft of History, Cambridge University Press, 2006].

Hoggart, R. (1970). La culture du pauvre, Paris : Minuit [trad. fr. Par F. et J.-C. Garcias et J.-C. Passeron de The Uses of Literacy: Aspects of Working-Class Life, Londres: Chatto, 1957].

Langage \& société n 133 (2010) « New Literacy Studies, un courant majeur sur l'écrit ».

Le français aujourd'hui $\mathrm{n}^{\circ} 170$ (2010). « Graphies : signes, gestes, supports ».

Le français aujourd'hui nº 174 (2011). « Penser à l'écrit ».

Pratiques n 131-132 (2006). « La littératie. Autour de Jack Goody ».

\section{NOTES}

1. Ces réflexions s'inscrivent dans la continuité de mon travail sur cette notion, pour l'essentiel désormais lisible dans un ouvrage récemment paru: L'écrit, la lecture et l'écriture: théories et didactiques, 2012, Paris : L'Harmattan, 260 p, particulièrement la quatrième partie "Des théories de l'écriture à la littératie".

\section{AUTEUR}

\section{JEAN-LOUIS CHISS}

Université de la Sorbonne Nouvelle Paris 3 (EA 2288, DILTEC)

Jean-Louis Chiss est professeur en sciences du langage au département DFLE qu'il a dirigé de 2008 à 2012 et directeur de l'UFR LLD. Il a dirigé l'EA 2288 (DILTEC) jusqu'en mars 2011. Ses recherches portent essentiellement sur l'enseignement/apprentissage du français langue maternelle, 
seconde et étrangère (didactique de la langue, des textes et discours), sur l'histoire et l'épistémologie des sciences du langage (spécifiquement linguistique et grammaires françaises depuis la fin du XIXe siècle jusqu'à aujourd'hui), ainsi que sur les théories du langage et leurs relations à la didactique du français et des langues. Il est l'auteur de l'ouvrage L'écrit, la lecture et l'écriture : théories et didactiques, paru à L'Harmattan en 2012.

Courriel : Jean-Louis.Chiss[at]univ-paris3.fr

Adresse : UFR Didactique du français langue étrangère, 46 rue Saint-Jacques 75005 Paris, France. 